\title{
Childhood Lung Function Predicts Adult Chronic Obstructive Pulmonary Disease and Asthma-Chronic Obstructive Pulmonary Disease Overlap Syndrome
}

\author{
Dinh S. Bui ${ }^{1}$, John A. Burgess ${ }^{1}$, Adrian J. Lowe ${ }^{1}$, Jennifer L. Perret ${ }^{1}$, Caroline J. Lodge ${ }^{1}$, Minh Bui ${ }^{1}$, Stephen Morrison ${ }^{2}$,
} Bruce R. Thompson ${ }^{3}$, Paul S. Thomas ${ }^{4}$, Graham G. Giles ${ }^{5}$, Judith Garcia-Aymerich ${ }^{6,7,8}$, Debbie Jarvis ${ }^{9,10}$, Michael J. Abramson ${ }^{11}$, E. Haydn Walters ${ }^{1,12}$, Melanie C. Matheson ${ }^{1 \star}$, and Shyamali C. Dharmage ${ }^{1 \star}$

${ }^{1}$ Allergy and Lung Health Unit, Centre for Epidemiology and Biostatistics, The University of Melbourne, Melbourne, Victoria, Australia; ${ }^{2}$ University of Queensland, Brisbane, Queensland, Australia; ${ }^{3}$ Department of Allergy, Immunology, and Respiratory Medicine, The Alfred Hospital, Melbourne, Victoria, Australia; ${ }^{4}$ University of New South Wales, Sydney, New South Wales, Australia; ${ }^{5}$ Cancer Epidemiology Centre, Cancer Council Victoria, Melbourne, Victoria, Australia; ${ }^{6}$ SGGlobal, Centre for Research in Environmental Epidemiology, Barcelona, Spain; ${ }^{7}$ Universitat Pompeu Fabra, Barcelona, Spain; ${ }^{8}$ Centros de Investigación Biomédica en Red Epidemiología y Salud Pública, Barcelona, Spain; ${ }^{9}$ Department of Epidemiology and Biostatistics, MRC-PHE Centre for Environment and Health, School of Public Health, Imperial College London, London, United Kingdom; ${ }^{10}$ Respiratory Epidemiology and Public Health Group, National Heart and Lung Institute, Imperial College London, London, United Kingdom; ${ }^{11}$ School of Public Health and Preventive Medicine, Monash University, Melbourne, Victoria, Australia; and ${ }^{12}$ School of Medicine, University of Tasmania, Hobart, Tasmania, Australia

\section{Abstract}

Rationale: The burden of chronic obstructive pulmonary disease (COPD) is increasing, yet there are limited data on early life risk factors.

Objectives: To investigate the role of childhood lung function in adult COPD phenotypes.

Methods: Prebronchodilator spirometry was performed for a cohort of 7-year-old Tasmanian children $(n=8,583)$ in 1968 who were resurveyed at 45 years, and a selected subsample $(n=1,389)$ underwent prebronchodilator and post-bronchodilator spirometry. For this analysis, COPD was spirometrically defined as a post-bronchodilator $\mathrm{FEV}_{1} / \mathrm{FVC}$ less than the lower limit of normal. Asthma-COPD overlap syndrome (ACOS) was defined as the coexistence of both COPD and current asthma. Associations between childhood lung function and asthma/COPD/ACOS were examined using multinomial regression.
Measurements and Main Results: At 45 years, 959 participants had neither current asthma nor COPD (unaffected), 269 had current asthma alone, 59 had COPD alone, and 68 had ACOS. The reweighted prevalence of asthma alone was $13.5 \%$, COPD alone $4.1 \%$, and ACOS $2.9 \%$. The lowest quartile of $\mathrm{FEV}_{1}$ at 7 years was associated with ACOS (odds ratio, 2.93; 95\% confidence interval, 1.32-6.52), but not COPD or asthma alone. The lowest quartile of $\mathrm{FEV}_{1} / \mathrm{FVC}$ ratio at 7 years was associated with ACOS (odds ratio, 16.3; 95\% confidence interval, 4.7-55.9) and COPD (odds ratio, 5.76; 95\% confidence interval, 1.9-17.4), but not asthma alone.

Conclusions: Being in the lowest quartile for lung function at age 7 may have long-term consequences for the development of COPD and ACOS by middle age. Screening of lung function in school age children may identify a high-risk group that could be targeted for intervention. Further research is needed to understand possible modifiers of these associations and develop interventions for children with impaired lung function.

Keywords: childhood lung function; early life; asthma-COPD overlap syndrome

(Received in original form June 25, 2016; accepted in final form February 1, 2017)

*These authors contributed equally.

Supported by the National Health and Medical Research Council (NHMRC) of Australia under NHMRC project grant scheme (299901 and 1021275) and NHMRC European collaborative grant scheme (1101313) as part of ALEC (Ageing Lungs in European Cohorts), funded by the European Union's Horizon 2020 research and innovation programme under grant 633212; The University of Melbourne; Clifford Craig Medical Research Trust of Tasmania; the Victorian, Queensland, and Tasmanian Asthma Foundations; The Royal Hobart Hospital; Helen MacPherson Smith Trust; and GlaxoSmithKline. The funding agencies had no direct role in the conduct of the study; the collection, management, statistical analysis, or interpretation of the data; or preparation or approval of the manuscript.

Author Contributions: Study concept and design, S.C.D., E.H.W., G.G.G., and M.J.A. Acquisition of data, S.C.D., E.H.W., M.C.M., J.A.B., P.S.T., and S.M. Analysis and interpretation of data, D.S.B., S.C.D., J.A.B., and M.C.M. Drafting of the manuscript, D.S.B., S.C.D., J.A.B., and M.C.M. Critical revision of the manuscript for important intellectual content, D.S.B., J.A.B., A.J.L., J.L.P., C.J.L., M.B., S.M., B.R.T., P.S.T., G.G.G., J.G.-A., D.J., M.J.A., E.H.W., M.C.M., and S.C.D. Statistical analysis, D.S.B., S.C.D., and J.A.B. Obtained funding, S.C.D., E.H.W., M.J.A., and S.M.

Correspondence and requests for reprints should be addressed to Shyamali C. Dharmage, Ph.D., Allergy and Lung Health Unit, Centre for Epidemiology and Biostatistics, The University of Melbourne, Parkville, Victoria 3052, Australia. E-mail: s.dharmage@unimelb.edu.au

This article has an online supplement, which is accessible from this issue's table of contents at www.atsjournals.org

Am J Respir Crit Care Med Vol 196, Iss 1, pp 39-46, Jul 1, 2017

Copyright @ 2017 by the American Thoracic Society

Originally Published in Press as DOI: 10.1164/rccm.201606-1272OC on February 1, 2017

Internet address: www.atsjournals.org 


\section{At a Glance Commentary}

\section{Scientific Knowledge on the}

Subject: People who enter adult life with lower lung function are at increased risk of chronic obstructive pulmonary disease (COPD) in later life even if the rate of lung function decline is normal. However, the role of childhood lung function on the risk of middle-age COPD phenotypes is not known.

\section{What This Study Adds to the}

Field: We found associations between childhood lung function and both adult COPD alone and asthma-COPD overlap syndrome. This suggests that prevention of COPD and asthmaCOPD overlap syndrome should be considered from early life, including measures targeted at maximization of childhood lung function.

Chronic obstructive lung diseases including asthma and chronic obstructive pulmonary disease (COPD) are major public health issues worldwide (1). COPD is among the leading causes of death, and asthma also imposes substantial morbidity and health care costs. Recently, asthmaCOPD overlap syndrome (ACOS) has received much interest, but its definition has been evolving. As defined in the current joint guideline of Global Initiative for Asthma and the Global Initiative for Chronic Obstructive Lung Disease (GOLD) (1), ACOS is "characterized by persistent airflow limitation with several features usually associated with asthma and several features usually associated with COPD." Origins of ACOS are complex and still poorly understood. It is suggested that ACOS can be the result of progression from long-term or severe asthma to fixed airflow obstruction (2-5). ACOS may be simply the coexistence of asthma and COPD because both conditions are common. It is also hypothesized that ACOS is a single disease entity and may be differentiated from asthma and COPD by biomarkers, such as exhaled nitric oxide (6). Compared with asthma or COPD alone, ACOS is more progressive in terms of frequency and severity of exacerbations, hospitalization, and poor quality of life (7-10).
Determining the causes for ACOS as opposed to asthma alone or COPD alone could help guide more targeted prevention and treatment. The role of early life determinants of asthma has been widely studied (11); however, there is increasing interest in early life origins of COPD. Fixed airflow obstruction is a common feature of COPD and ACOS, and it is therefore plausible that early life lung function may play a role in the etiology of both conditions.

Longitudinal studies have shown that poor lung function in early life tracks into early adulthood $(12,13)$. Furthermore, it is now increasingly recognized that people entering adult life with incomplete lung growth are at increased risk of COPD, even in the absence of rapid decline during adult life (14). A study by Lange and coworkers (15) of three independent cohorts compared lung function before the age of 40 years with subsequent lung function decline and COPD 22 years later. Half the people with COPD had a normal decline in $\mathrm{FEV}_{1}$ but started from a lower baseline level of $\mathrm{FEV}_{1}$. Similarly, another study by Kalhan and coworkers (16) found that impaired lung function in subjects between 18 and 30 years of age predicted COPD 20 years later. The Melbourne Epidemiological Study of Childhood Asthma (17) reported that at the age of 50 years, subjects with COPD or current asthma showed evidence of lower lung function from childhood compared with subjects without asthma and those in remission from asthma, but ACOS was not examined. It is possible that lower lung function in early life is related to COPD and ACOS in adult life, but to date, no study has directly investigated this association.

We aimed to investigate associations between childhood lung function and current asthma, spirometrically defined COPD, and ACOS, and to estimate the prevalence of these conditions in early middle-age. Some of the results of this study have been previously reported in the form of an abstract (18).

\section{Methods}

\section{Study Design and Population}

This analysis used data from TAHS (Tasmanian Longitudinal Health Study). The study methodology has been reported in detail elsewhere (19). In brief, TAHS began in 1968 when 8,583 Tasmanian children born in 1961 and attending school in Tasmania were studied with surveys and prebronchodilator (BD) spirometry. The most recent survey started in 2002 when the original 1968 cohort was retraced and resurveyed. A sample of respondents enriched for asthma and cough participated in a laboratory study from 2006 to 2008, which included a questionnaire and pre-BD and post-BD spirometry. The 1,389 participants with post-BD spirometry comprise the sample for this analysis (see METHODS in the online supplement).

This study was approved by the Human Ethics Review Committees at The Universities of Melbourne (approval number 040375), Tasmania (040375.1), New South Wales (08094), the Alfred Hospital (1118/04), and Royal Brisbane and Women's Hospital Health Service District (2006/037).

\section{Lung Function Measurements}

Lung function tests, including pre-BD and post-BD spirometry were conducted according to the joint American Thoracic Society and European Respiratory Society guidelines (20). The predicted and \% predicted values for spirometry were derived from the Global Lung Initiative reference equations (21), which have been validated in an Australian population (22).

\section{Definitions}

At age 45 years, current asthma was defined as having a positive response to the question "have you ever had asthma?" plus any asthma symptom or asthma medication use in the last 12 months. Participants who denied asthma history at 45 years, but had reported asthma in any of previous followups and were using asthma medication at 45 years were also considered as current asthma

COPD at age 45 years was defined as post-BD $\mathrm{FEV}_{1} / \mathrm{FVC}$ less than the Global Lung Initiative lower limit of normal. Smoking was not included as a criterion in the COPD definition.

Participants were categorized into four mutually exclusive groups based on their asthma and COPD status: (1) neither asthma nor COPD (unaffected), (2) asthma alone, (3) COPD alone, and (4) ACOS. Thus, ACOS included all participants with both COPD and current asthma. 
Definitions of other variables are available in the online supplement.

\section{Statistical Analysis}

Characteristics of participants were compared across four groups defined at follow-up (45 yr) (unaffected, asthma alone, COPD alone, and ACOS) using chi-square tests for categorical variables and analysis of variance for continuous variables where appropriate.

Multinomial regression models were fitted to investigate associations between childhood lung function parameters at 7 years and asthma/COPD/ACOS at 45 years. Lung function parameters were converted to \% predicted values. Because associations between childhood lung function and both ACOS and COPD alone were nonlinear, quartiles were used. The final multinomial model was adjusted for childhood lung infections, childhood asthma, maternal smoking, paternal smoking during childhood, and childhood socioeconomic status. Interactions were tested between childhood lung function and each of childhood asthma, maternal asthma, maternal smoking, paternal smoking during childhood, childhood lung infections, and adult active smoking, by including interaction terms into the model and using likelihood ratio tests.

Population prevalence and 95\% confidence intervals (CI) for the entire Tasmanian population born in 1961 were extrapolated back from the observed prevalences by reweighting the known sampling fractions derived from the 1968, 1974 , and 2002 surveys.

Lung function from 7 to 45 years was compared cross-sectionally among the four designated groups. Missing values for lung function at 13 and 18 years were multiply imputed (20 imputations).

All analyses were performed using Stata version 13.0 (Stata Corp., College Station, TX).

\section{Results}

\section{Population Prevalence of COPD Alone, ACOS, and Asthma Alone} Of the 1,389 participants with post-BD lung function data available at 45 years, 1,355 had information about current asthma status. Of these, 959 participants had neither current asthma nor COPD (unaffected), 269 participants had current asthma alone, 59 participants had COPD alone, and 68 participants had ACOS. Once adjusted for the sampling weights, the prevalence of current asthma alone was $13.5 \%$ (95\% CI, 11.8-15.4), COPD alone 4.1\% (95\% CI, 3.0-5.5), and ACOS 2.9\% (95\% CI, 2.2-3.7) (Figure 1). Therefore, among COPD population, ACOS accounted for $41 \%[2.9 /(2.9+4.1)]$.

\section{Demographic and Clinical Characteristics}

There was no difference in age among the four designated groups. More of the asthma alone group were female than other groups. History of active smoking was significantly more frequent in ACOS (73.5\%) and COPD alone (73\%) than in unaffected (57\%) groups. Childhood asthma, maternal asthma, and atopy were more prevalent in the ACOS and asthma alone groups. Median age (interquartile range) at asthma onset was 6 (2-24) and 4 (2-11) years for asthma alone and ACOS participants, respectively. Childhood lung infection was not significantly different across the four groups. ACOS and COPD participants had a higher prevalence of maternal smoking during childhood. Almost all ACOS (92.6\%) and asthma alone (80.2\%) participants had used inhaled medicines for breathing problems in the last 12 months, whereas it was not reported at all by COPD alone or unaffected participants. Within each clinical group, there was a fairly consistent reduction of post-BD lung function indices at 45 years compared with the unaffected group, with ACOS having the highest reduction, although not all between-group comparisons were significant (Table 1).

\section{Longitudinal Tracking of Lung Function among the Designated Groups}

Pre-BD lung function from 7 years to 45 years among study participants is shown in Figure 2. Participants with ACOS had the lowest pre-BD $\mathrm{FEV}_{1}$ (\% predicted values) over time. Participants with COPD alone or ACOS had significantly lower pre$\mathrm{BD} \mathrm{FEV}_{1} / \mathrm{FVC}$ (\% predicted values) at all four time points compared with unaffected participants. Participants with COPD alone had significantly higher FVC at 7 and

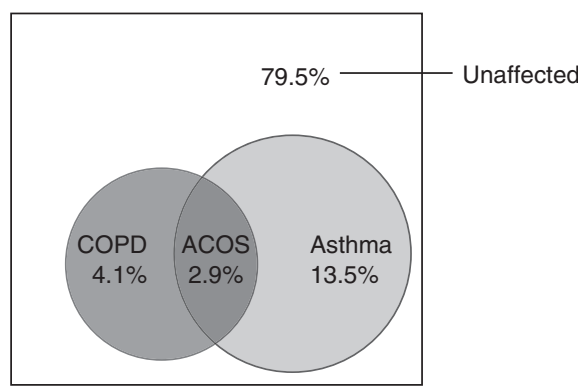

Figure 1. Nonproportional Venn diagram of reweighted population prevalence of asthma, COPD, and ACOS (sample sizes for unaffected, asthma alone, COPD alone, and ACOS groups were 959, 269, 59, and 68, respectively). ACOS = asthma-COPD overlap syndrome; $\mathrm{COPD}=$ chronic obstructive pulmonary disease

13 years, whereas ACOS participants had significantly lower FVC at 45 years.

\section{Associations between Childhood Lung Function and the Designated Groups}

Associations were observed between $\mathrm{FEV}_{1} / \mathrm{FVC}$ ratio at 7 years and both COPD alone (odds ratio [OR], 5.76; 95\% CI, 1.9-17.4) and ACOS (OR, 16.3; 95\% $\mathrm{CI}, 4.7-55.9$ ), whereas $\mathrm{FEV}_{1}$ at 7 years was strongly associated with only ACOS (OR, 2.93; 95\% CI, 1.32-6.52) but not with COPD alone (Table 2). In contrast, lung function at 7 years was not associated with current asthma alone. These findings did not change significantly after adjustment was made for active asthma or asthma severity at 7 years instead of presence/absence of asthma. Associations between childhood lung function and COPD alone, and ACOS remained significant after additional adjustment for sampling weights.

There was no evidence of effect modification by childhood lung infections, childhood asthma, maternal asthma, maternal smoking, or paternal smoking during childhood on the associations between childhood lung function and the disease groups (all $P$ values for interaction $>0.1)$.

Because there was a large variation in childhood lung function values among the lowest quartiles of $\mathrm{FEV}_{1}$ and $\mathrm{FEV}_{1} / \mathrm{FVC}$, a sensitivity analysis was conducted after excluding those with less than $80 \%$ predicted $(n=76$ and $n=13$, respectively). In this analysis, the 
Table 1. Characteristics of Participants According to Outcome Groups

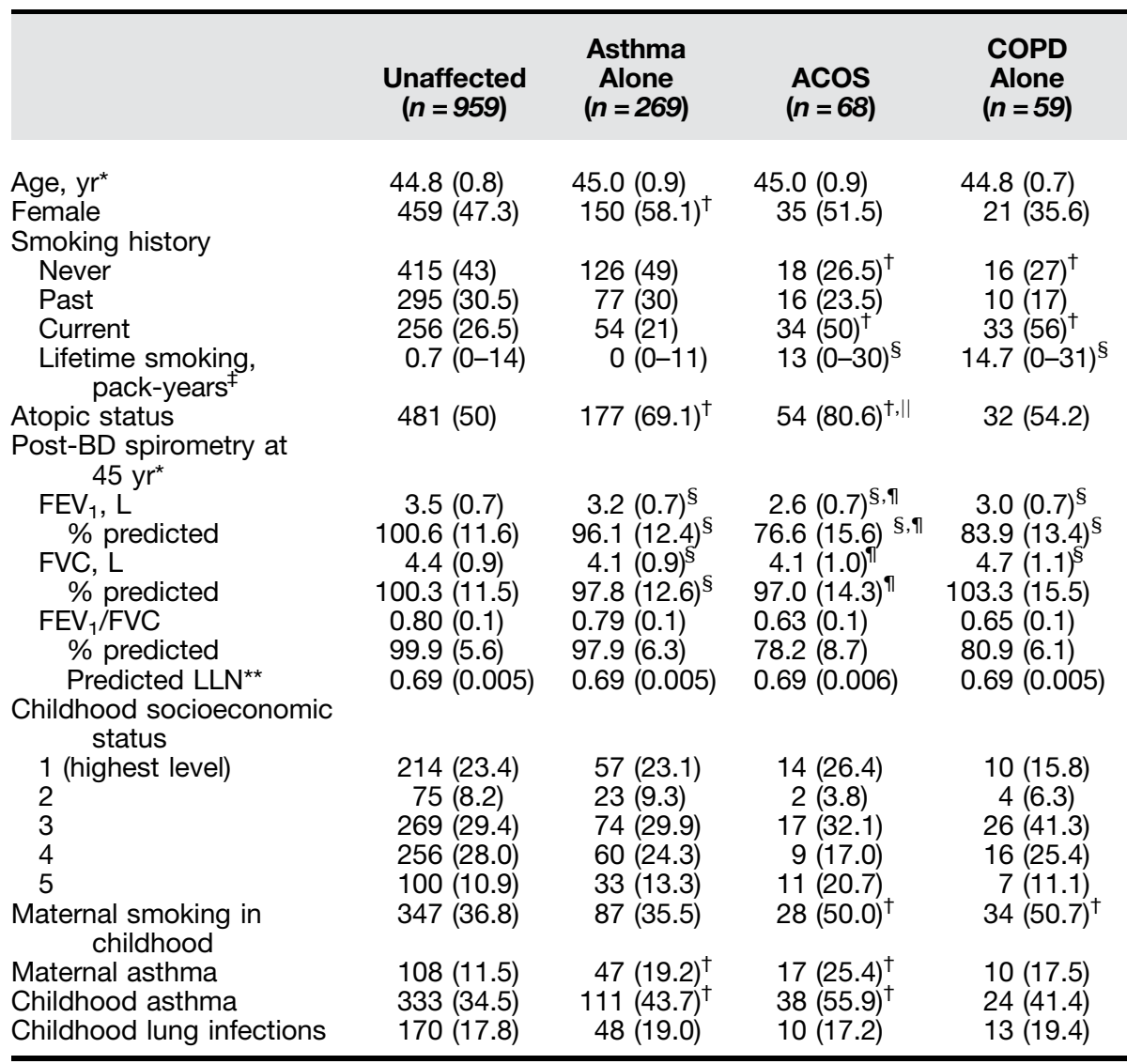

Definition of abbreviations: ACOS = asthma-COPD overlap syndrome; BD = bronchodilator;

$\mathrm{COPD}=$ chronic obstructive pulmonary disease; $L L N=$ lower limit of normal.

Data are presented as $\mathrm{n}(\%)$ unless otherwise indicated.

${ }^{\star}$ Mean (SD).

${ }^{\dagger} P<0.05$ compared with unaffected by Pearson $2 \times 2$ chi-square test.

${ }^{\ddagger}$ Median (interquartile range).

$\S P<0.05$ compared with unaffected by Bonferroni multiple comparison test.

$\| P<0.05$ compared with COPD by Pearson $2 \times 2$ chi-square test.

" $P<0.05$ compared with COPD.

${ }^{*} \mathrm{LLN}$ represents the fifth percentile or $1.645 \mathrm{SD}$ below the predicted mean of values.

observed lowest quartile associations of $\mathrm{FEV}_{1}$ (ACOS: OR, 2.4; 95\% CI, 1.02-5.7) and $\mathrm{FEV}_{1} / \mathrm{FVC}(\mathrm{COPD}$ alone: OR, 5.2; 95\% CI, 1.7-16.0; and ACOS: OR, 15.1; 95\% CI, 4.4-52.0) changed only slightly. Another sensitivity analysis that excluded remitted asthma from the control group (the unaffected group) showed stronger associations. Childhood $\mathrm{FEV}_{1}$ was associated with ACOS (OR, 7.0; 95\% CI, 2.7-18.3 for the lowest vs. the highest quartile), whereas childhood $\mathrm{FEV}_{1} / \mathrm{FVC}$ was associated with COPD (OR, 6.8; 95\% CI, 2.1-21.8 for the lowest quartile) (OR, 3.9; 95\% CI, 1.2-13.1 for the second quartile) and ACOS (OR, 19.1; 95\% CI,
$5.2-70.5$ for the first quartile) (OR, 5.3; 95\% CI, 1.2-21.2 for the second quartile).

\section{Potential Effect Modification of the Observed Associations between Childhood Lung Function and COPD (and ACOS) by Smoking Status}

We further investigated the association between childhood $\mathrm{FEV}_{1} / \mathrm{FVC}$ and middleage COPD after stratifying by personal smoking status. We observed ORs of 7.8 (95\% CI, 0.95-68; $P=0.06)$ in neversmokers and 5.0 (95\% CI, 1.4-19; $P=0.02$ ) in ever-smokers, but the difference in the estimates was not significant $(P$ value for interaction $=0.9$ ). We also observed a higher proportion of COPD never-smokers (64\%) than of COPD ever-smokers $(38 \%)$ to have lower childhood $\mathrm{FEV}_{1} / \mathrm{FVC}$ (see Table E1 in the online supplement).

However, we were unable to conduct a similar stratified analysis by smoking status for the association between childhood lung function and ACOS because of limited sample size in the never-smoking ACOS group.

\section{Comparison of Spirometrically Defined COPD with GOLD Clinical Criteria}

According to GOLD guidelines for the diagnosis, management, and prevention of COPD (23), key indicators for considering a diagnosis of COPD include dyspnea, chronic cough, chronic sputum production, family history of COPD, and a history of exposure to risk factors for the disease (i.e., tobacco smoke, smoke from home cooking and heating fuels, or occupational dusts and chemicals). An individual older than 40 years of age with any of key indicators should be diagnosed as COPD if spirometry confirms the presence of persistent airflow limitation. In our study, 95\% of COPD participants (97\% of COPD alone and $93 \%$ of ACOS) had at least one key indicator, thus fulfilling the GOLD clinical diagnosis of COPD.

\section{Discussion}

\section{Principal Findings}

This study shows that lower lung function at age 7 years is associated with an increased risk of COPD and ACOS by middle age. To our knowledge, this is the first report of lower childhood lung function as a risk factor for adult COPD and ACOS, providing further evidence on the early life origins of these diseases.

\section{Definition of Outcomes}

In clinical practice, symptoms and history of exposure to risk factors are taken into account in COPD diagnosis. However, in this study, the definition of COPD was solely based on spirometry to have a sensitive definition. Because the population was relatively young, symptoms were not included to avoid missing asymptomatic participants. Smoking was not part of the definition to include both 

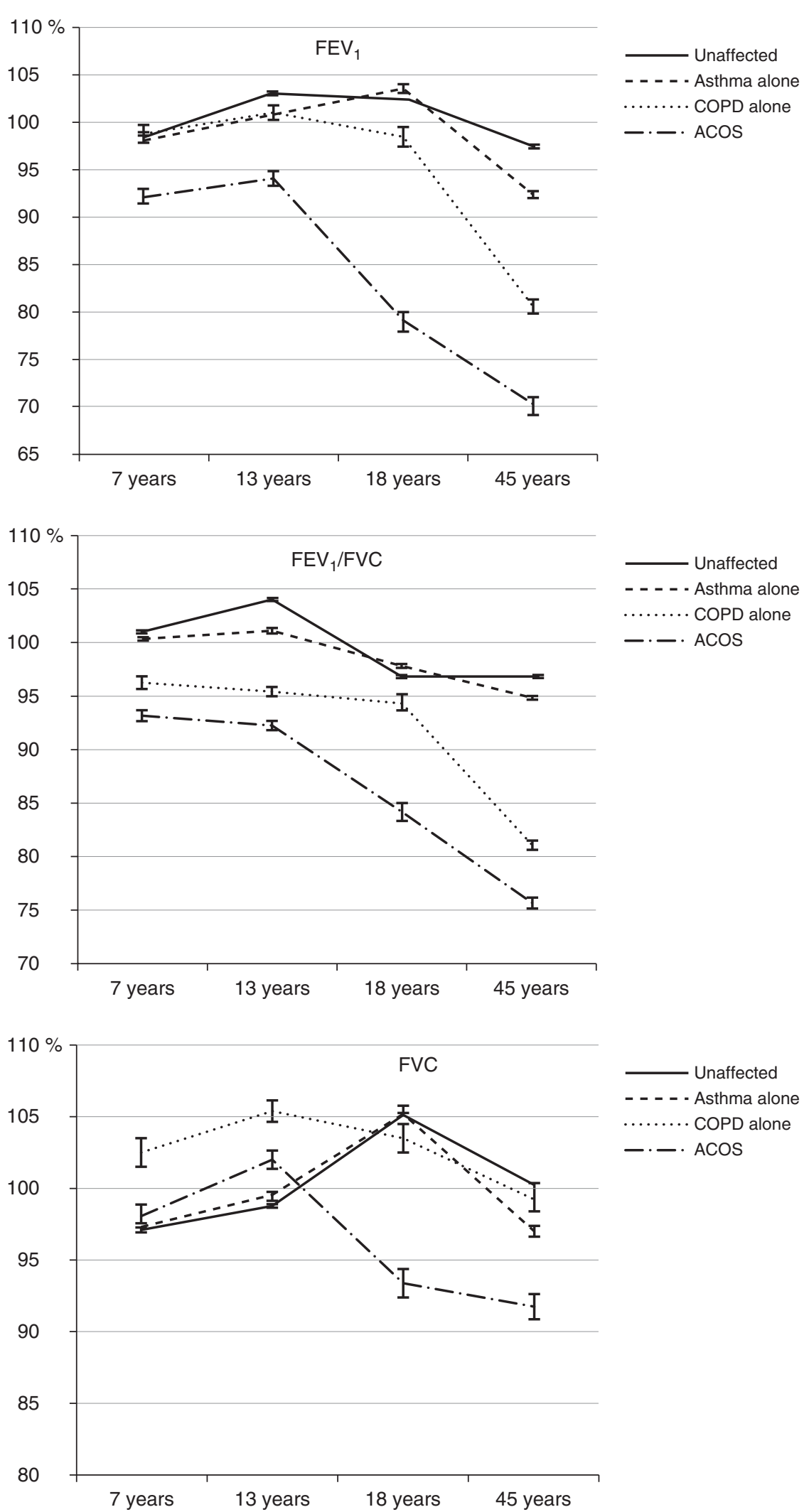

Figure 2. Cross-sectional comparison of prebronchodilator lung function (mean and 95\% confidence interval of \% predicted values) for the four designated groups. ACOS = asthma-COPD overlap syndrome; COPD = chronic obstructive pulmonary disease. smoking-related and non-smoking-related phenotypes. One might argue that the term fixed airflow limitation or chronic airflow limitation should be used when only the post-BD spirometry is used to identify the cases. However, $95 \%$ of the participants categorized as COPD in this study fulfilled the GOLD clinical definition of COPD as having at least one key indicator for a diagnosis of COPD plus fixed airflow limitation (23). Although our definition may have overestimated the number of COPD (and ACOS) participants, this is likely to be random across exposure categories. Therefore, if anything, the associations with childhood lung function may have been underestimated.

\section{Prevalence of Outcomes}

We estimated the reweighted prevalence of ACOS and COPD alone to be $2.9 \%$ and $4.1 \%$, respectively, at 45 years of age. Few studies have attempted to quantify the prevalence of ACOS and it would be expected to vary depending on age and definition. Studies have investigated ACOS among patients with COPD and have reported its prevalence to be between 15 and $55 \%$ (24-27). Our estimate of $41 \%$ is within this range. Whether ACOS can be seen as an independent disease entity, a form of severe asthma, or simply coexistence of the two common conditions remains a question for debate $(7,8)$. In our study, the reweighted prevalence of ACOS is higher than the probability of having both asthma and COPD, suggesting that ACOS is not just the coexistence of asthma and COPD by chance alone.

\section{Associations between Childhood Lung Function and COPD and ACOS}

Our study is the first to examine the link between early life lung function and ACOS We found that ACOS participants showed evidence of persistently lower $\mathrm{FEV}_{1}$ and $\mathrm{FEV}_{1} / \mathrm{FVC}$ from childhood. This suggests that poorer childhood lung function tracked to early adult life, leading to impaired maximally attained lung function. This in turn leads to poorer lung function in middle age, even when lung function decline is not accelerated.

Our finding on the associations between lung function at age 7 years and COPD bridges the gap between earlier findings of Stern and coworkers (12) and others $(15,16)$. Following the Tucson birth cohort longitudinally, Stern and 
Table 2. Association between Childhood Lung Function and Adult Asthma Alone, COPD Alone, and Asthma-COPD Overlap Syndrome

\begin{tabular}{|c|c|c|c|c|c|c|}
\hline & \multicolumn{2}{|c|}{ Asthma Alone } & \multicolumn{2}{|c|}{ Acos } & \multicolumn{2}{|c|}{ COPD Alone } \\
\hline & n (\%) & OR $(95 \% \mathrm{Cl})$ & n (\%) & OR (95\% Cl) & n (\%) & OR (95\% Cl) \\
\hline \multicolumn{7}{|l|}{$\mathrm{FEV}_{1 \%}$ predicted at $7 \mathrm{yr}$} \\
\hline $\begin{array}{l}\text { Highest (fourth) quartile } \\
\text { (107-137) }\end{array}$ & $53(23)$ & 1 & $10(17)$ & 1 & $13(25)$ & 1 \\
\hline Third quartile (98.8-107.0) & $61(27)$ & $1.32(0.85-2.04)$ & $10(17)$ & $0.96(0.36-2.57)$ & $13(25)$ & $0.92(0.39-2.16)$ \\
\hline Second quartile (90.4-98.8) & $53(23)$ & $1.11(0.70-1.75)$ & 11 (18) & $1.22(0.48-3.06)$ & $10(20)$ & $0.80(0.33-1.98)$ \\
\hline First quartile (54.0-90.4) & $61(27)$ & $1.10(0.70-1.75)$ & $29(48)$ & $2.93(1.32-6.52)^{*}$ & $15(29)$ & $1.09(0.46-2.55)$ \\
\hline \multicolumn{7}{|l|}{$\mathrm{FEV}_{1} / \mathrm{FVC} \%$ predicted at $7 \mathrm{yr}$} \\
\hline $\begin{array}{l}\text { Highest (fourth) quartile } \\
(104.5-113)\end{array}$ & $52(23)$ & 1 & $3(5)$ & 1 & $5(10)$ & 1 \\
\hline Third quartile (100.9-104.5) & $64(28)$ & $1.00(0.65-1.54)$ & $7(12)$ & $2.09(0.51-8.5)$ & $8(16)$ & $2.25(0.67-7.4)$ \\
\hline Second quartile (96.5-100.9) & $51(22)$ & $0.88(0.56-1.36)$ & $11(18)$ & $3.32(0.86-12.7)$ & $14(27)$ & $2.76(0.86-8.9)$ \\
\hline First quartile (67.2-96.5) & $61(27)$ & $1.03(0.65-1.61)$ & $39(65)$ & $16.3(4.7-55.9)^{t^{\prime}}$ & $24(47)$ & $5.76(1.90-17.4)^{*}$ \\
\hline \multicolumn{7}{|l|}{ FVC $\%$ predicted at $7 \mathrm{yr}$} \\
\hline $\begin{array}{l}\text { Highest (fourth) quartile } \\
(105-146)\end{array}$ & $62(27)$ & 1 & $17(28)$ & 1 & $20(39)$ & 1 \\
\hline Third quartile (97.7-105) & $52(23)$ & $0.91(0.58-1.41)$ & $12(20)$ & $0.54(0.24-1.23)$ & $7(14)$ & $0.32(0.13-0.78)^{\ddagger}$ \\
\hline Second quartile (90.1-97.7) & $57(25)$ & $0.94(0.60-1.48)$ & $16(27)$ & 0.72 (0.33-1.58) & $14(27)$ & $0.46(0.20-1.05)$ \\
\hline First quartile (54.2-90.1) & $57(25)$ & $0.91(0.58-1.43)$ & $15(25)$ & $0.68(0.31-1.47)$ & $10(20)$ & $0.41(0.17-0.97)^{\ddagger}$ \\
\hline
\end{tabular}

Definition of abbreviations: $\mathrm{ACOS}=$ asthma-COPD overlap syndrome; $\mathrm{Cl}=$ confidence interval; $\mathrm{COPD}=$ chronic obstructive pulmonary disease;

$\mathrm{OR}=$ odds ratio.

Data are presented with healthy participants as reference group, adjusting for childhood lung infection, childhood asthma, maternal smoking, paternal smoking, and childhood socioeconomic status.

${ }^{\star} P<0.01$.

${ }^{\dagger} P<0.001$

${ }^{\ddagger} P<0.05$.

coworkers (12) reported that poor lung function shortly after birth tracked to age 22 years. Kalhan and coworkers (16) reported a link between poor lung function in early adulthood and subsequent COPD. Lange and coworkers (15) found half of COPD cases could be attributed to low lung function in adulthood even without steeper lung function decline. Adding to the wellrecognized pathway to COPD from steep lung function decline, we now provide evidence of another long-term pathway to COPD from poor lung function in childhood. Moreover, our data show that those who developed COPD by middle age had persistently lower $\mathrm{FEV}_{1} / \mathrm{FVC}$ over time from childhood (Figure 2), which is consistent with the observation by Tai and coworkers (17).

This study highlights that low childhood lung function is a risk factor for COPD (and ACOS) independent of smoking. It has been reported that the effect of cigarette smoking on lung function decline with age is most evident in young adults with preexisting airflow obstruction (16). Furthermore, it has also been shown that reduced lung function in infancy is associated with wheeze at 18 years, only in smokers (28). We observed the effect of lower childhood lung function on subsequent COPD to be greater in never-smokers than ever-smokers but a test for interaction between childhood lung function and smoking was not statistically significant. However, the small sample size might have limited the statistical power. It is also possible that the intensity of smoking in smokers may have differed between our study and others.

A complex relationship exists among asthma, lung function, COPD, and ACOS. On one hand, childhood asthma has been associated with impaired childhood lung function (29), adult asthma, and COPD (30). Moreover, poor lung function has been described as a marker of asthma severity and more severe asthma was strongly associated with COPD (17). However, childhood asthma or its severity did not confound our results. On the other hand, both childhood asthma $(31,32)$ and poor childhood lung function (13) may result from impaired lung function at birth. Therefore, a synergistic effect between poor childhood lung function and "early life asthma background" or "asthma predisposing factors" may also contribute to COPD and
ACOS development. However, we did not observe any such effect modification by childhood asthma or maternal asthma. However, because of the small sample sizes for the COPD alone and ACOS groups, we cannot rule out the possibility of such interaction.

In our study, participants with asthma or ACOS had the highest prevalence of atopy as would be expected. However, the prevalence of atopy was also high in COPD and unaffected participants. This is partly because our sample was enriched for asthma and cough. However, our reweighted population prevalence of atopy was also high, which is consistent with Australia being among countries with the highest prevalence of atopy (33). We did not observe atopy to be an effect modifier for associations between childhood lung function and COPD or ACOS.

The age of the participants in our study was younger than in most clinical trials in COPD. Our participants, therefore, may represent an early form/stage of COPD of relatively low prevalence. Consistently, mild COPD was predominant in our study, with $70 \%$ of the COPD alone group having $\mathrm{FEV}_{1}$ greater than or equal 
to $80 \%$ of predicted values, which is substantially higher than reported elsewhere $(34,35)$. Moreover, we observed that participants with COPD alone did not report any medication use for breathing problems in the prior year. Reporting no medication use could just reflect underdiagnosis and undertreatment, which is common in early COPD (35-37).

\section{Strengths and Limitations}

Our study has strengths and limitations. The main strength is that TAHS is one of the world's longest-running cohort studies in which data on lung function and respiratory health have been collected prospectively from childhood. Using information about asthma status at multiple follow-ups helps minimize misclassification of asthma because of recall bias (38). The use of post-BD spirometry to define COPD at age 45 years is also a strength of this study compared with the use of pre-BD spirometry by other studies (2), which also looked at COPD and ACOS.

The relatively small sample sizes for the ACOS and COPD alone groups are a limitation. In addition, like most other studies initiated in that era, we did not have post-BD spirometry at 7 years. However, any potential that our data were confounded by the $\mathrm{BD}$ response that might have been seen in more active asthma was taken into account by analyses allowing for the presence of childhood asthma and asthma severity. There was a large variation in lung function values in the lowest quartiles of $\mathrm{FEV}_{1}$ and $\mathrm{FEV}_{1} / \mathrm{FVC}$, but the sensitivity analysis confirmed that our observed associations were not driven by those with extremely low lung function.

\section{Conclusions}

Our study is the first to show that lower lung function in early life may have long-term consequences for the development of COPD and ACOS by middle age. Our study suggests that screening of lung function in school-age children may provide an opportunity to detect children likely to have ongoing poorer lung health, such as those with lung function below the lower limit of normal. Multifaceted intervention strategies could then be implemented to reduce the burden of
COPD and ACOS in adulthood.

Further research is needed to better understand the risk factors for lower lung function in children and also further understanding of risk factors over adulthood that interact with lower lung function to increase the risk of rapid lung function decline.

Author disclosures are available with the text of this article at www.atsjournals.org.

Acknowledgment: The authors acknowledge the TAHS (Tasmanian Longitudinal Health Study) participants and previous investigators. They thank Professor Mark Jenkins, Ph.D., Centre for Epidemiology \& Biostatistics, The University of Melbourne, Victoria, and Dr. lain Feather, Gold Coast Hospital, Queensland, who are TAHS investigators, but not coauthors of this manuscript, for their assistance with obtaining funds and data collection. They also acknowledge all the respiratory scientists who collected data in the lung function laboratories of Tasmania, Victoria, Queensland, and New South Wales; the research interviewers and data entry operators; and the organizational roles of Ms. Cathryn Wharton and Dr. Desiree Mészáros. Finally, they thank the Archives Office of Tasmania for providing data from the 1968 TAHS questionnaires.

\section{References}

1. Global Initiative for Asthma - Global Initiative for Chronic Obstructive Lung Disease. Diagnosis of diseases of chronic airflow limitation: asthma, COPD and asthma-COPD overlap syndrome (ACOS); 2014 [accessed 2015 Dec 12]. Available from: http://www.goldcopd.org

2. de Marco R, Marcon A, Rossi A, Antó JM, Cerveri I, Gislason T, Heinrich J, Janson C, Jarvis D, Kuenzli N, et al. Asthma, COPD and overlap syndrome: a longitudinal study in young European adults. Eur Respir $J$ 2015;46:671-679.

3. Perret JL, Dharmage SC, Matheson MC, Johns DP, Gurrin LC, Burgess JA, Marrone J, Markos J, Morrison S, Feather I, et al. The interplay between the effects of lifetime asthma, smoking, and atopy on fixed airflow obstruction in middle age. Am J Respir Crit Care Med 2013;187:42-48.

4. Silva GE, Sherrill DL, Guerra S, Barbee RA. Asthma as a risk factor for COPD in a longitudinal study. Chest 2004;126:59-65.

5. Aanerud M, Carsin AE, Sunyer J, Dratva J, Gislason T, Jarvis D, deMarco R, Raherison C, Wjst M, Dharmage SC, et al. Interaction between asthma and smoking increases the risk of adult airway obstruction. Eur Respir $J$ 2015;45:635-643.

6. Karampitsakos T, Gourgoulianis KI. Asthma-COPD overlap syndrome (ACOS): single disease entity or not? Could exhaled nitric oxide be a useful biomarker for the differentiation of ACOS, asthma and COPD? Med Hypotheses 2016;91:20-23.

7. Nielsen $M$, Bårnes $C B$, Ulrik CS. Clinical characteristics of the asthmaCOPD overlap syndrome: a systematic review. Int J Chron Obstruct Pulmon Dis 2015:10:1443-1454.

8. Alshabanat A, Zafari Z, Albanyan O, Dairi M, FitzGerald JM. Asthma and COPD overlap syndrome (ACOS): a systematic review and meta analysis. PLoS One 2015;10:e0136065.

9. Global Initiative for Asthma. COPD and asthma-COPD overlap syndrome (ACOS); 2014 [accessed 2015 Sep 10]. Available from: http://www. ginasthma

10. Tho NV, Park HY, Nakano Y. Asthma-COPD overlap syndrome (ACOS): a diagnostic challenge. Respirology 2015;21:410-418.
11. Svanes C, Sunyer J, Plana E, Dharmage S, Heinrich J, Jarvis D, de Marco R, Norbäck D, Raherison C, Villani S, et al. Early life origins of chronic obstructive pulmonary disease. Thorax 2010;65:14-20.

12. Stern DA, Morgan WJ, Wright AL, Guerra S, Martinez FD. Poor airway function in early infancy and lung function by age 22 years: a nonselective longitudinal cohort study. Lancet 2007;370:758-764.

13. Turner SW, Palmer LJ, Rye PJ, Gibson NA, Judge PK, Young S, Landau LI, Le Souëf PN. Infants with flow limitation at 4 weeks: outcome at 6 and 11 years. Am J Respir Crit Care Med 2002;165: 1294-1298.

14. Postma DS, Bush A, van den Berge M. Risk factors and early origins of chronic obstructive pulmonary disease. Lancet 2015;385:899-909.

15. Lange P, Celli B, Agustí A, Boje Jensen G, Divo M, Faner R, Guerra S, Marott JL, Martinez FD, Martinez-Camblor P, et al. Lung-function trajectories leading to chronic obstructive pulmonary disease. $N$ Engl J Med 2015;373:111-122.

16. Kalhan R, Arynchyn A, Colangelo LA, Dransfield MT, Gerald LB, Smith LJ. Lung function in young adults predicts airflow obstruction 20 years later. Am J Med 2010;123:468.

17. Tai A, Tran H, Roberts M, Clarke N, Wilson J, Robertson CF. The association between childhood asthma and adult chronic obstructive pulmonary disease. Thorax 2014;69:805-810.

18. Bui DS, Burgess JA, Lowe AJ, Lodge CJ, Perret JL, Abramson MJ, Morrison S, Thomas PS, Walters EH, Matheson MC, et al. Lower childhood lung function predicts middle-age COPD and asthmaCOPD overlap syndrome [abstract]. Respirology 2016;21:62.

19. Matheson MC, Abramson MJ, Allen K, Benke G, Burgess JA, Dowty JG, Erbas B, Feather IH, Frith PA, Giles GG, et al.; TAHS investigator group. Cohort profile: the Tasmanian Longitudinal Health STUDY (TAHS). Int J Epidemiol [online ahead of print] 6 Jun 2016; DOI: 10.1073/ije/dyw028.

20. Miller MR, Hankinson J, Brusasco V, Burgos F, Casaburi R, Coates A, Crapo R, Enright P, van der Grinten CP, Gustafsson P, et al.; ATS/ERS Task Force. Standardisation of spirometry. Eur Respir J 2005;26:319-338. 
21. Quanjer PH, Stanojevic S, Cole TJ, Baur X, Hall GL, Culver BH, Enright PL, Hankinson JL, Ip MSM, Zheng J, et al.; ERS Global Lung Function Initiative. Multi-ethnic reference values for spirometry for the 3-95-yr age range: the global lung function 2012 equations. Eur Respir J 2012;40:1324-1343.

22. Hall GL, Thompson BR, Stanojevic S, Abramson MJ, Beasley R, Coates A, Dent A, Eckert B, James A, Filsell S, et al. The Global Lung Initiative 2012 reference values reflect contemporary Australasian spirometry. Respirology 2012;17:1150-1151.

23. Global Initiative for Chronic Obstructive Lung Disease. Global strategy for the diagnosis, management, and prevention of COPD; 2016 [accessed $2016 \mathrm{Apr}$ 9]. Available from: http://www.goldcopd.org

24. Soriano JB, Davis KJ, Coleman B, Visick G, Mannino D, Pride NB. The proportional Venn diagram of obstructive lung disease: two approximations from the United States and the United Kingdom. Chest 2003;124:474-481.

25. Marsh SE, Travers J, Weatherall M, Williams MV, Aldington S, Shirtcliffe PM, Hansell AL, Nowitz MR, McNaughton AA, Soriano JB, et al. Proportional classifications of COPD phenotypes. Thorax 2008;63:761-767.

26. Kauppi $P$, Kupiainen $H$, Lindqvist $A$, Tammilehto $L$, Kilpelainen $M$, Kinnula VL, Haahtela T, Laitinen T. Overlap syndrome of asthma and COPD predicts low quality of life. J Asthma 2011;48:279-285.

27. Hardin M, Silverman EK, Barr RG, Hansel NN, Schroeder JD, Make BJ, Crapo JD, Hersh CP; COPDGene Investigators. The clinical features of the overlap between COPD and asthma. Respir Res 2011;12:127.

28. Mullane D, Turner SW, Cox DW, Goldblatt J, Landau LI, le Souëf PN. Reduced infant lung function, active smoking, and wheeze in 18-year-old individuals. JAMA Pediatr 2013;167:368-373.

29. Covar RA, Spahn JD, Murphy JR, Szefler SJ; Childhood Asthma Management Program Research Group. Progression of asthma measured by lung function in the childhood asthma management program. Am J Respir Crit Care Med 2004;170:234-241.
30. Tai A. Childhood asthma and chronic obstructive pulmonary disease: outcomes until the age of 50. Curr Opin Allergy Clin Immunol 2015; 15:169-174.

31. Håland G, Carlsen KC, Sandvik L, Devulapalli CS, Munthe-Kaas MC Pettersen M, Carlsen KH; ORAACLE. Reduced lung function at birth and the risk of asthma at 10 years of age. N Engl J Med 2006;355:1682-1689.

32. Bisgaard $\mathrm{H}$, Jensen SM, Bønnelykke $\mathrm{K}$. Interaction between asthma and lung function growth in early life. Am J Respir Crit Care Med 2012;185:1183-1189.

33. Bumey P, Malmberg E, Chinn S, Jarvis D, Luczynska C, Lai E. The distribution of total and specific serum IgE in the European Community Respiratory Health Survey. J Allergy Clin Immunol 1997;99:314-322.

34. Shahab L, Jarvis MJ, Britton J, West R. Prevalence, diagnosis and relation to tobacco dependence of chronic obstructive pulmonary disease in a nationally representative population sample. Thorax 2006;61:1043-1047.

35. Miravitlles M, Soriano JB, García-Río F, Muñoz L, Duran-Tauleria E, Sanchez G, Sobradillo V, Ancochea J. Prevalence of COPD in Spain: impact of undiagnosed COPD on quality of life and daily life activities. Thorax 2009;64:863-868.

36. Hvidsten SC, Storesund L, Wentzel-Larsen T, Gulsvik A, Lehmann S. Prevalence and predictors of undiagnosed chronic obstructive pulmonary disease in a Norwegian adult general population. Clin Respir J 2010;4:13-21.

37. Decramer M, Miravitlles M, Price D, Román-Rodríguez M, Llor C, Welte T, Buhl R, Dusser D, Samara K, Siafakas N. New horizons in early stage COPD: improving knowledge, detection and treatment. Respir Med 2011;105:1576-1587.

38. Burgess JA, Walters EH, Byrnes GB, Wharton C, Jenkins MA, Abramson MJ, Hopper JL, Dharmage SC. Who remembers whether they had asthma as children? J Asthma 2006; 43:727-730. 
Reproduced with permission of copyright owner. Further reproduction prohibited without permission. 